\title{
IDENTIFICAÇÃO DE SOJA TOLERANTE A GLYPHOSATE ATRAVÉS DO TESTE DE GERMINAÇÃO
}

\author{
Gilberto A. P. Bevilaqua ${ }^{1}$, Emidio R. Bonato ${ }^{2}$ \\ e Erivelton S. Roman ${ }^{3}$
}

\author{
1 Eng. Agr., Dr., Técnico de Nível Superior. Embrapa Trigo. Rodovia BR 285, km 174. Caixa Postal 451. Passo Fundo, RS $99001-970$. \\ bevilaq@cnpt.embrapa.br \\ 2 Eng. Agr., Dr., Pesquisador. Embrapa Trigo. bonato@enpt.embrapa.br \\ 3 Eng. Agr., Ph.D., Pesquisador. Embrapa Trigo. eroman (a)cnpt.embrapa.br
}

\section{RESUMO}

Objetivando reduzir o tempo necessário para verificar a presença do gene de tolerância ao herbicida glyphosate (RR), através da aplicação do produto em plantas de soja, ou o custo envolvido na verificação via análise de DNA, em sementes viáveis, realizou-se pesquisa para desenvolver metodologia para identificação de sementes de soja tolerantes a glyphosate em teste de germinação padrão. Foram usadas sementes de seis genótipos sensíveis a glyphosate e de 12 genótipos tolerantes. Os tratamentos foram: aplicação em pulverização cotiledonar/foliar de solução de glyphosate, na concentração de $8960 \mathrm{mg} / \mathrm{l}$, em volume de $100 \mathrm{l} /$ ha de calda (equivalente a $2 \mathrm{~g} / \mathrm{ha}$ ), no quinto dia do início do teste de germinação; aplicação de glyphosate na água de embebição do papel de germinação, nas concentrações de 0, 280, 560, 1120, 2240, 4480, 6720 e 8960 mg/l. As unidades experimentais foram rolos de papel germiteste, contendo 50 sementes, com oito repetições, totalizando 400 sementes, exceto no tratamento de pulverização foliar, que foram 25 sementes em linha, semeadas no terço superior do papel de germinação. O papel de germinação foi pesado e acrescentou-se solução de glyphosate, nas concentrações estudadas, em volume equivalente a três vezes o peso do papel. O período de avaliação foi de oito dias. Os parâmetros avaliados foram a percentagem de plântulas normais, anormais e mortas. O estudo evidenciou que é possível identificar a presença de sementes de soja tolerantes a glyphosate (RR) pelo teste de germinação em laboratório e que a dose de glyphosate a ser usada no teste é $280 \mathrm{mg} / \mathrm{l}$ na água de embebição do substrato de germinação.

Palavras-chave: Glycine max, herbicida, avaliação, resistência.

\section{ABSTRACT \\ Identification of glyphosate-tolerant soybean plants through germination test}

Since DNA tests are relatively expensive and time-consuming for the detection of the presence of the gene in plant materials confering glyphosate tolerance to soybean, an experiment was carried out with the objective of developing a rapid and simple laboratory test for identifying glyphosate-tolerant soybean seeds, through standard seed germination tests. Seeds from six susceptible and twelve glyphosate-tolerant genotypes were used. The treatments consisted of cotiledonar/foliar spray of a glyphosate solution at the concentration of $8960 \mathrm{mg} / \mathrm{l}$ with $100 \mathrm{l} / \mathrm{ha}$ spray volume (equivalent to $2 \mathrm{~g} / \mathrm{ha}$ ) on the fifth day from the beginning of the germination test and soaking of the germination paper with glyphosate solutions at the concentrations of 0 , $280,560,1120,2240,4480,6720$, and $8960 \mathrm{mg} / \mathrm{l}$. The experimental units consisted of rolled germtest paper containing 50 seeds, replicated 8 times, except for the foliar spray treatment where 25 seeds were lined on the first third of the germtest paper. The germtest paper was weighed and the glyphosate solutions were added according to the treatments, in volume equivalent to 
three times the paper weight. Percentage of normal, abnormal and dead seedlings was assessed for eight days, by which time germination had ceased. This research demonstrated that it is possible to detect the presence of glyphosate-tolerant soybean seeds by the lab germination test using glyphosate at the rate of $280 \mathrm{mg} /$ liter of the imbibition water.

Key words: Glycine max, herbicide, resistence, evaluation.

\section{INTRODUÇÃO}

Segundo James (1998), citado por Zanettini \& Pasquali (s.d.), milho e soja são as principais culturas nas quais estão sendo desenvolvidas pesquisas sobre transgenia, principalmente soja resistente a herbicida e milho a ataque de insetos. A estimativa era de que a área mundial cultivada com transgênicos alcançasse 27 milhões de hectares, em 1998. O desenvolvimento de plantas transgênicas tem grande potencial por oferecer benefícios na prática agrícola, na qualidade de alimentos, na nutrição e na saúde. O principal motivo que levou à suspensão do direito à comercialização de soja transgênica foi a falta de certeza quanto à segurança alimentar desse produto e seus efeitos a longo prazo sobre o organismo humano (Brasil, 1999).

As culturas tolerantes a herbicidas dão aos produtores a flexibilidade de aplicá-los somente quando necessário, de reduzir o seu uso e de empregar produtos com características ambientais desejáveis. O glyphosate é um herbicida de rápida degradação devido à forte ligação com as partículas de solo e à atuação de microorganismos, enquanto outros produtos usados possuem alto poder residual para controle de plantas daninhas antes e após a emergência de plântulas (Monsanto, 1997; WSSA, 1983).

O glyphosate é um herbicida não seletivo, altamente efetivo contra a maioria das plantas daninhas, gramíneas anuais e perenes ou latifoliadas. A aplicação é em pós-emergência de plantas daninhas, podendo, em algumas espécies, ser realizada até o início do florescimento. Para grandes culturas, como soja e trigo, a semeadura pode ser feita imediatamente após a aplicação de glyphosate, pois o produto é adsorvido pelo solo, não ficando disponível para a planta (Rodrigues \& Almeida, 1998). O herbicida é absorvido pela folha e translocado na planta, não sendo metabolizado na planta (WSSA, 1983).

Segundo Padgette et al. (1995), o glyphosate inibe a enzima 5-enolpiruvil shiquimato-3-fosfato sintase (EPSP sintase ou EPSPS) e impede a planta de formar aminoácidos aromáticos, essenciais para a síntese de proteínas, e alguns metabólitos secundários (Holländer \& Amrhein, 1980). Haderlie et al. (1977) concluíram que ocorre inibição do efeito do glifosato sobre o crescimento de células de cenoura e de fumo pela adição de três aminoácidos aromáticos, sendo esse o principal efeito do herbicida sobre a planta. Entretanto, Duke et al. (1980) concluíram que o glyphosate exerce alguns de seus efeitos através da redução do "pool" de aminoácidos aromáticos através do aumento da atividade da enzima fenilalaninaamonialiase (PAL) e que nem todo o efeito de inibição do crescimento do glyphosate é devido à redução de aminoácidos aromáticos.

Rápida acumulação de shiquimato foi observada em plantas sensíveis ao glyphosate (Singh \& Shaner, 1998; Holländer \& Amrhein, 1980). Por outro lado, plantas resistentes ao herbicida mostraram diminuição nos níveis de shiquimato (Singh \& Shaner, 1998). A soja tolerante a glyphosate é obtida pela expressão da enzima EPSPS (Padgette et al., 1995). O gene inserido, em plantas tolerantes a glyphosate, aumenta a quantidade da enzima, fornecendo um desvio ao redor do bloqueio, tornando possível que a planta se desenvolva normalmente após a aplicação do herbicida, enquanto as plantas sensíveis são eliminadas.

Westwood et al. (1997) observaram variação na suscetibilidade a glyphosate entre biotipos de Convolvulus arvensis. Essa variação pode estar relacionada à presença e à espessura de cera cuticular que afetaria a absorção do herbicida. Embora os biótipos sensíveis e tolerantes apresentem igual absorção e translocação do glyphosate, o biótipo sensível é inerentemente mais suscetível que o outro.

A Embrapa Trigo tem recebido grande número de amostras de grãos de soja apreendidas pela fiscalização do Ministério da Agricultura e do Abastecimento, as quais são utilizadas como sementes. As amostras de sementes são submetidas a teste para comprovação da presença do gene de tolerância a glyphosate, em casa-de-vegetação, em vasos, com a aplicação do herbicida aos 40 dias após a semeadura, procedimento que torna a caracterização da reação ao herbicida pouco prática e muito demorada. No caso de a amostra ser de material verde, os testes são realizados mediante a extração de DNA. Nesse caso, os testes são rápidos, mas de custo muito elevado, exigindo mão-de-obra e laboratório especializados. $\mathrm{O}$ protocolo com o uso de material genético proveniente de sementes ainda é pouco utilizado.

Assim, o objetivo do trabalho foi estabelecer metodologia simples, rápida e eficiente para identificar a presença do gene de tolerância a glyphosate (RR) em sementes de soja, através do teste de germinação.

\section{MATERIAL E MÉTODOS}

Os estudos foram realizados no Laboratório de Análise de Sementes da Embrapa Trigo, entre novembro de 1999 e abril de 2000, usando-se sementes de soja (Glycine max L. Merrill) das cultivares convencionais BRS 66 , BRS 153, BRS 154, BR16, CD 203 e BRS 205, sensíveis ao glyphosate, e de 12 
genótipos previamente identificados como tolerantes a glyphosate (com o gene RR).

No primeiro estudo foram usadas sementes da cv. BRS 66 e do genótipo 01, tolerante a glyphosate, e três tratamentos: embebição do substrato de germinação em solução de glyphosate na concentração de $8960 \mathrm{mg} / 1$, pulverização foliar/ cotiledonar no quinto dia do início do teste de germinação de uma solução de glyphosate na concentração de 8960 mg/l, e uma testemunha sem tratamento. As unidades experimentais foram rolos de papel germiteste, com 25 sementes dispostas em linha, com 16 repetições, totalizando 400 sementes. As sementes foram colocadas no terço superior do rolo de papel, de maneira que ficassem visíveis no momento da aplicação do tratamento.

No segundo estudo foram usadas sementes da cv. BRS 66 e do genótipo 02 e oito concentrações de glyphosate na água de embebição do papel de germinação $(0,280,560,1120$, $2240,4480,6720$ e $8960 \mathrm{mg} / \mathrm{l}$ ) em um esquema fatorial $2 \times 8$. As unidades experimentais foram rolos de papel germiteste contendo 50 sementes, com oito repetições, totalizando 400 sementes.

No terceiro estudo foram usadas sementes da cv. BRS 66, dos genótipos 01 e 02 e de uma amostra de soja proveniente da Argentina e três doses de glyphosate: 0, 280 e $560 \mathrm{mg} / \mathrm{l}$. No quarto estudo foram usadas sementes das cvs. BRS 153, BRS 154, CD 203, BR-16 e BRS 205 e de 12 genótipos e duas doses de glyphosate: 0 e $280 \mathrm{mg} / \mathrm{l}$. Em ambos os casos, as unidades experimentais foram rolos de papel germiteste contendo 50 sementes, com oito repetições, totalizando 400 sementes.

O substrato de germinação (papel germiteste) foi pesado e acrescentou-se a solução de glyphosate, com as concentrações definidas para cada estudo, em volume equivalente a três vezes o peso do papel seco (Brasil, 1992). Não foi aplicado tratamento fungicida pois esse não é recomendado para avaliação do poder germinativo (Brasil, 1992).

Os parâmetros avaliados foram: a) percentagem de plântulas normais que apresentaram desenvolvimento de raiz primária e algumas raízes secundárias ou ausência de raiz primária e muitas raízes secundárias, que certamente irão sobreviver, no campo, sob condições favoráveis; b) percentagem de plântulas anormais; c) percentagem de plântulas mortas.

\section{RESULTADOS E DISCUSSÃO}

Os resultados do primeiro estudo mostraram que as sementes dos dois genótipos apresentaram poder germinativo acima de $90 \%$ quando foi realizado o teste padrão de germinação (Tabela 1). Com o uso de glyphosate a $8960 \mathrm{mg} / \mathrm{l}$ na água de embebição do substrato, a germinação de sementes da cv. BRS 66 foi zero, e a do genótipo 01 foi de 7\%. Por outro lado, foi observado o aparecimento de 4 e $90 \%$ de plântulas anormais na soja sensível e na tolerante a glyphosate, respectivamente. Ocorreram, também, $96 \%$ de plântulas mortas na cv.
Tabela 1. Efeito do herbicida glyphosate nos resultados do teste de germinação em plântulas normais $(\mathrm{N})$, anormais (A) e mortas (M), em sementes de soja. Embrapa Trigo, Passo Fundo, RS. 2000.

\begin{tabular}{|c|c|c|c|c|c|c|}
\hline \multirow{3}{*}{$\begin{array}{c}\text { Tratamento } \\
\text { (mg/l) }\end{array}$} & \multicolumn{6}{|c|}{ Plântulas (\%) } \\
\hline & \multicolumn{3}{|c|}{ BRS 66} & \multicolumn{3}{|c|}{ Genótipo 01} \\
\hline & $\mathbf{N}$ & $\mathbf{A}$ & $\mathbf{M}$ & $\mathbf{N}$ & A & $\mathbf{M}$ \\
\hline 0 & 92 & 5 & 3 & 94 & 5 & 2 \\
\hline 8960 & 0 & 4 & 96 & 7 & 90 & 3 \\
\hline 8960 (pulverização foliar) & 0 & 2 & 98 & 93 & 5 & 2 \\
\hline
\end{tabular}

BRS 66 , contra apenas $3 \%$ na linhagem com o gene RR. Esses resultados demonstram que a dose de glyphosate foi elevada, apesar de permitir diferenciar a amostra de semente tolerante ao herbicida.

O tratamento de pulverização cotiledonar/foliar da solução de glyphosate a 8960 mg/l mostrou-se eficiente em diferenciar a amostra de soja sensível da tolerante ao herbicida, pois todas as plântulas normais de soja convencional morreram na avaliação final. Entretanto, devido à prolongada duração do teste (14 dias), houve aparecimento de infecções secundárias por microorganismos, prejudicando a avaliação de plântulas. Segundo Singh \& Shaner (1998), o glyphosate é herbicida de ação lenta, podendo levar cerca de 10 a 20 dias para a planta morrer, embora WSSA (1994) coloque que sintomas de fitotoxicidade aparecem entre 2 e 4 dias, em plantas anuais. Assim, optou-se por continuar os estudos com os testes de embebição do papel de germinação.

No segundo estudo a dose de $280 \mathrm{mg} / \mathrm{l}$ de glyphosate ocasionou $\quad 0 \%$ de plântulas normais e $27 \%$ de anormałs, na cv. BRS 66 (Tabela 2). Já na dose de 560 mg/l de glyphosate,

Tabela 2. Percentagem de plântulas normais $(\mathrm{N})$ e anormais (A) com uso de glyphosate no teste de germin ção de sementes de genótipos de soja sensíveis e tolerantes ao herbicida. Embrapa Trigo, Passo Fundo, RS. 2000.

\begin{tabular}{|c|c|c|c|c|}
\hline \multirow{3}{*}{$\begin{array}{c}\text { Glyphosate } \\
\text { (mg/l) }\end{array}$} & \multicolumn{4}{|c|}{ Plântulas (\%) } \\
\hline & \multicolumn{2}{|c|}{ Genótipo 02} & \multicolumn{2}{|c|}{ BRS 66} \\
\hline & $\mathbf{N}$ & $\mathbf{A}$ & $\mathbf{N}$ & $\mathbf{A}$ \\
\hline 0 & 97 & 3 & 92 & 3 \\
\hline 280 & 94 & 5 & 0 & 27 \\
\hline 560 & 97 & 2 & 0 & 9 \\
\hline 1120 & 86 & 14 & 0 & 4 \\
\hline 2240 & .70 & 25 & 0 & 6 \\
\hline 4480 & 0 & 96 & 0 & 5 \\
\hline 6720 & 0 & 99 & 0 & 4 \\
\hline 8960 & 0 & 99 & 0 & 4 \\
\hline
\end{tabular}


ocorreram 0\% de plântulas normais e 9\% de anormais, com aumento considerável de plântulas mortas, em relação à dose de $280 \mathrm{mg} / \mathrm{l}$. No genótipo 02, até à dose de $560 \mathrm{mg} / \mathrm{l}$ não houve efeito negativo sobre o índice de plântulas normais, demonstrando não haver efeito fitotóxico de glyphosate nos genótipos com o gene RR. Entretanto, nas doses de 1120 e 2240 mg/l ocorreram 14 e $25 \%$ de plântulas anormais, e nas doses superiores a $2240 \mathrm{mg} / 1$, houve apenas plântulas anormais, o que demonstra doses excessivas, verificando-se efeito tóxico do herbicida sobre as plântulas. A dose a ser usada para diferenciar genótipos sensíveis e tolerantes deve situar-se entre 280 e $560 \mathrm{mg} / \mathrm{l}$.

Os sintomas observados revelam que as sementes de cultivares convencionais iniciam o processo germinativo e, após atingirem um tamanho de $5 \mathrm{~cm}$, paralisam o crescimento e começa um escurecimento do hipocótilo até haver a morte de plântulas. Isso permite que em amostras com mistura de sementes, possam ser identificadas as cultivares convencionais e as tolerantes a glyphosate (RR), pois haverá três tipos de plântulas no teste de germinação com o uso de glyphosate: as normais, as anormais e aquelas que iniciam o processo germinativo, as quais alcançam certo crescimento, tornam-se escurecidas e morrem.

Sementes com baixo poder germinativo dificultam, eventualmente, a avaliação das plântulas tolerantes a glyphosate e a interpretação do teste de germinação, sendo necessária a inclusão de uma testemunha sem o uso do glyphosate. Em sementes com baixo poder germinativo, o método a ser usado é o de análise de DNA.

O terceiro estudo, conforme observado na Tabela 3, mostra que na dose $280 \mathrm{mg} / \mathrm{l}$ foi possível diferenciar as sementes de genótipo tolerantes dos sensíveis a glyphosate, sem ocorrência de plântulas anormais, pois $100 \%$ das plântulas de soja convencional morreram, enquanto nos genótipos tolerantes houve germinação normal, sem qualquer efeito tóxico. Nenhum genótipo tolerante apresentou sensibilidade à dose mais baixa de glyphosate; entretanto, Westwood et al. (1997) observaram variação na suscetibilidade ao herbicida entre biótipos de Convolvulus arvensis, de quatro vezes entre os mais e os menos sensíveis, apresentando inerentemente maior

Tabela 3. Percentagem de plântulas normais (N) e anormais (A) com uso de glyphosate no teste de germinação de sementes de genótipos de soja sensíveis e tolerantes ao herbicida. Embrapa Trigo, Passo Fundo, RS. 2000.

\begin{tabular}{|c|c|c|c|c|c|c|}
\hline \multirow{3}{*}{$\begin{array}{c}\text { Glyphosate } \\
\text { (mg/l) }\end{array}$} & \multicolumn{6}{|c|}{ Plântulas (\%) } \\
\hline & \multicolumn{2}{|c|}{ BRS 66} & \multicolumn{2}{|c|}{ Genótipo 01} & \multicolumn{2}{|c|}{ Argentina } \\
\hline & $\mathbf{N}$ & $\mathbf{A}$ & $\mathbf{N}$ & $\mathbf{A}$ & $\mathbf{N}$ & $\mathbf{A}$ \\
\hline 0 & 92 & 3 & 94 & 3 & 43 & 4 \\
\hline 280 & 0 & 27 & 95 & 3 & 42 & 8 \\
\hline 560 & 0 & - & 95 & 3 & 45 & 6 \\
\hline
\end{tabular}

suscetibilidade. Assim, um ajuste de dose pode ser necessário, até $560 \mathrm{mg} / \mathrm{l}$ de glyphosate na solução de embebição do papel de germinação, para aqueles genótipos convencionais que são tolerantes a doses mais elevadas de glyphosate.

O genótipo proveniente da Argentina, apreendido pela fiscalização do Ministério da Agricultura e do Abastecimento, mostrou $43 \%$ de poder germinativo, no teste padrão (Tabela 3 ). Isso se deve provavelmente ao período de armazenamento das sementes na Embrapa Trigo, superior a um ano em condições ambientais de Passo Fundo. Este fato pode ter comprometido a qualidade fisiológica das sementes, ocasionando o aparecimento de elevado índice de plântulas anormais e alta incidência de fungos nas amostras. De qualquer maneira, a percentagem de plântulas normais manteve-se quando o substrato foi embebido com solução de 280 e $560 \mathrm{mg} / \mathrm{l}$ de glyphosate.

De acordo com os resultados do quarto estudo, Tabela 4 , as variedades convencionais sem o gene de tolerância a glyphosate (RR), mostraram 0\% de plântulas normais no teste de germinação com o uso de $280 \mathrm{mg} / \mathrm{l}$ de glyphosate, ao passo que os demais genótipos mostraram poder germinativo acima de $85 \%$, revelando sua tolerância a glyphosate. Os genótipos 10,11 e 12 apresentaram poder germinativo mais elevado com o uso de glyphosate, em relação ao teste de germinação padrão, enquanto os demais genótipos apresentaram resultados semelhantes com e sem o uso de glyphosate. Esse fato indica que glyphosate aplicado no teste de germinação de sementes tolerantes ao herbicida pode apresentar efeito benéfico sobre

Tabela 4. Percentagem de plântulas normais $(\mathrm{N})$ e anormais (A) com uso de glyphosate no teste de germinação de sementes de genótipos de soja sensíveis e tolerantes ao herbicida. Embrapa Trigo, Passo Fundo, RS. 2000.

\begin{tabular}{cccccr}
\hline & \multicolumn{4}{c}{ Plântulas (\%) } \\
\cline { 2 - 3 } Genótipo o & \multicolumn{3}{c}{ Testemunha } & & \multicolumn{2}{c}{$\mathbf{2 8 0} \mathbf{~ m g / 1 ~}$} \\
\cline { 2 - 3 } \cline { 5 - 6 } & N & $\mathbf{A}$ & & N & A \\
\hline 03 & 89 & 5 & & 88 & 5 \\
04 & 97 & 1 & & 93 & 7 \\
05 & 98 & 1 & & 95 & 1 \\
06 & 96 & 3 & & 98 & 0 \\
07 & 97 & 2 & & 93 & 4 \\
08 & 96 & 3 & & 82 & 11 \\
09 & 97 & 2 & & 99 & 0 \\
10 & 90 & 6 & & 97 & 1 \\
11 & 90 & 4 & & 99 & 0 \\
12 & 71 & & & 96 & 0 \\
PF 93263 & 88 & 6 & & 0 & 95 \\
BRS 154 & 84 & 5 & & 0 & 80 \\
CD 203 & 94 & 3 & & 0 & 92 \\
BR 16 & 99 & 0 & & 0 & 98 \\
BRS 153 & 96 & 2 & & 0 & 95 \\
\hline
\end{tabular}


a germinação de sementes, sendo necessários alguns testes suplementares. Por outro lado, o genótipo 08 apresentou germinação mais baixa com o uso de glyphosate, o que pode indicar mistura de sementes de cultivares convencionais ou segregação nas plantas para esta característica.

\section{CONCLUSÕES}

É possível detectar a presença de sementes de soja transgênica através do teste de germinação em laboratório. A dose de glyphosate a ser usada no teste é de $280 \mathrm{mg} / \mathrm{l}$ na água de embebição do papel de germinação.

\section{LITERATURA CITADA}

BRASIL. Ministério da Agricultura e Reforma Agrária. Regras de análise de sementes. Brasília: MA/DNPV/CLAV, 1992.545p.

BRASIL. Ministério da Ciência e Tecnologia. Transgênicos. Brasília: Ministério da Ciência e Tecnologia/Comissão Técnica Nacional de Biossegurança, 1999. 48p.

DUKE, S.O.; HOAGLAND, R.E.; ELMORE, D. Effects of glyphosate on metabolism of phenolic compounds. V. L?-aminooxy-?-phenylpropionic acid and glyphosate effects on phenyl-alanine ammonia-lyase in soybeans seedlings. Plant Physiology, v. 65, p.17-21, 1980.

HADERLIE, L.C.; WIDHOLM, J.M.; SLIFE, F.W. Effect of glyphosate on carrot and tobacco cells. Plant Physiology, Madison, v.60, p.40-43, 1977.
HOLLÄNDER, H.; AMRHEIN, N. The site of the inhibition of the shikimate pathway by glyphosate. I. Inhibition by glyphosate of phenylpropanoid synthesis in buckwheat (Fagopyrum esculentum Moench). Plant Physiology, Madison, v.66, p.823-829, 1980.

MONSANTO. Biotecnologia: soluções para o mundo de amanhã. São Paulo: Monsanto do Brasil Ltda., novembro, 1997.28p.

PADGETTE, S.R.; KOLACZ, K.H.; DELANNAY, D.B.. Development, identification, and characterization of a glyphosate-tolerant soybean line. Plant Physiology, Madison, v.35,n.5, p.1461-1467, 1995.

RODRIGUES, B.N.; ALMEIDA, F.S. Guia de herbicidas. 4ed. Londrina, PR: Iapar, 1998.648p.

SINGH, B.K.; SHANER, D.L. Rapid determination of glyphosate injury to plants and identification of glyphosate-resistant plants. Weed Technology, v.12, p.527-530, 1998.

WEED SCIENCE SOCIETY OF AMERICA. Herbicide handbook. Champaign, IL: W.S.S.A., 7ed, 1994.352p.

WESTWOOD, J.H.; YERKES, C.N.; DeGENNARO, F.P.; WELLER, S.C. Absorption and translocation of glyphosate in tolerant and susceptible biotypes of field bindweed (Convolvulus arvensis). Weed Science, v. 45, p.658-663, 1997.

ZANETTINI, M.H.B., PASQUALI, G. Plantas transgênicas: uma nova ferramenta para o melhoramento genético vegetal. Porto Alegre: Farsul/SENAR, Universidade Federal do Rio Grande do Sul. 18p., s.d. 